Vietnam Journal of Mechanics, VAST, Vol.29, No. 2 (2007), pp. 73-82

\title{
ORTHOGONAL-BASED WAVELET ANALYSIS OF WIND TURBULENCE AND CORRELATION BETWEEN TURBULENCE AND FORCES
}

\author{
LE THAI HOA \\ Wind Engineering Laboratory, \\ Graduate School of Engineering, Kyoto University, Japan \\ NGUYEN DONG ANH \\ Institute of Mechanics, \\ Vietnamese Academy of Science and Technology, Vietnam
}

\begin{abstract}
Recent models of wind turbulence and turbulence-force relation as well still contain uncertainties. Further studies on them are needed to gain the better knowledge to refine the existing problems from analytical computations to wind tunnel's physical simulations in the wind engineering. The continuous and discrete wavelet transforms have been applied as powerful transformation tools to represent time series into the timefrequency localization. This paper will apply the orthogonal-based wavelet decomposition to investigate the intermittency of the turbulence and to detect the turbulence-force correlation in the both temporal-spectral information using proposed cross energy of wavelet decompositions. Analyzing data have been obtained by physical measurements on model from the wind tunnel tests.
\end{abstract}

\section{INTRODUCTION}

Uncertainty exists in the recent models of wind turbulence and turbulent-induced forces to produce overestimation or underestimation of random aerodynamic response of structures. It is assumed that the induced forces are proportional to the instantaneous fluctuating velocities (turbulent components) and the attacked direction of turbulent flow as content of the quasi-steady theory. This theory is consistent, however, only if there are simultaneous correspondences between turbulence and turbulent-induced forces not in the frequency domain, but the time domain. So far, moreover, turbulence and induced forces has usually been studied based on the spectral transformation that is only valid for stationary time series. Wavelet Transforms (WT) have been recently developed as mathematical tools, based on a convolution operation between an original time series and an analyzing function, called wavelet or mother wavelet [4]. The WT advantages over the conventional spectral transformations such as Fourier Transform (FT) and Short-Time Fourier Transform (STFT) in simultaneously time-frequency analysis with flexible resolutions. The WT becomes powerful analyzing tool for stationary, non-stationary, intermittent time series, especially, to find out hidden short events inside the time series. Because of its advantages, the WT have been applied in the various fields such as digital signal processing, image coding and compressing [1,2], numerical analysis and digital simulation $[8,9,10$, 12], system and flow identification [5] and so on, and they still are increasingly evolving. The first idea to use the WT for studying atmospheric turbulence proposed by [6] 
to develop some tools such as local intermittency and energy of wavelet decompositions, wavelet power spectrum. Camussi and Guj [3] carried out the wavelet decompositions with orthogonal-based wavelets to permit the identification of the time information of coherent structures of artificial turbulence. Hajj [7] also used the orthogonal-based wavelets, moreover, to decompose the time series of turbulence into different scales and to investigate an extent of energy intermittency of prominent scales which contain most of energy. Correlation between atmospheric turbulence and turbulent-induced pressure has been discussed in frequency domain by [11] using higher-order Fourier transform tools. Previous literatures $[7,11]$ commented natural existence of the non-stationary characteristics of turbulence and the nonlinear cross-bicoherence between turbulence and induced pressure. Cross correlation between turbulence and induced pressure or forces in time-frequency plane, accordingly, using the WT tools need to be studied as logical development.

In this paper, the discrete wavelet transform using orthogonal-based wavelets will be presented with its applications on the time-frequency analysis of artificial turbulence, especially, correlation between turbulence and turbulent-induced forces. Furthermore, some concepts such as energy of wavelet decomposition, energy of intermittency, cross energy between two wavelet decompositions are going to be considered. Analyzing data of turbulence and turbulent-induced forces have been obtained by physical measurements from the wind tunnel tests.

\section{DISCRETE WAVELET TRANSFORM AND MULTI-RESOLUTION ANALYSIS}

Continuous wavelet transform (CWT) of a given time series $f(t)$ is defined as a convolution operation between the time series $f(t)$ and a wavelet function $\psi_{\tau, s}(t)$ :

$$
\Psi_{f}^{\psi}(\tau, s)=\left\langle f, \psi_{\tau, s}\right\rangle=\int_{-\infty}^{\infty} f(t) \cdot \psi_{\tau, s}^{*}(t) d t
$$

where $\Psi_{f}^{\psi}(s, \tau)$ : wavelet transform coefficient at translation $\tau$ and scale $\mathrm{s}$ in the time-scale plane; the brackets $\left\langle\right.$ denote the convolution operation; the asterisk ${ }^{*}$ means complex conjugate; $\psi_{\tau, s}(t)$ : wavelet function at translation $\tau$ and scale $\mathrm{s}$ of the basic wavelet function $\psi(t)$, also known as the mother wavelet:

$$
\psi_{\tau, s}(t)=\frac{1}{\sqrt{s}} \psi\left(\frac{t-\tau}{s}\right) .
$$

In the CWT, the time series $f(t)$ is sampled continuously on all over time-scale plane. Thus, the CWT creates a lot of redundant information and time consumption. The time and the scale parameters should be discretized in a mutual dependence and with respect to the Nyquist's sampling rule. A binary logarithmic disretization (dyadic grid) is commonly used due to octave by octave computational procedure:

$$
s=2^{m}, \tau=n 2^{m}(m, n=1,2,3 \ldots \text {; refer to scale level and location of wavelets). }
$$

Thus, the CWT is computed in this dyadic grid of the time-scale plane. From (2.2), (2.3) we have the wavelet function in the dyadic grid space:

$$
\psi_{m n}(t)=2^{-\frac{m}{2}} \cdot \psi\left(2^{-m} t-n\right)
$$


When the wavelets set an orthogonal basis, it means $\int_{-\infty}^{\infty} \psi_{k l}(t) \cdot \psi_{m n}(t) \cdot d t=\delta_{k m} \cdot \delta_{l \mathrm{n}}$ $\left(\delta_{k m}, \delta_{\mathrm{ln}}:\right.$ Kronecker deltas), any time series $f(t)$ can be decomposed from the convolution operation (2.1) due to following sums:

$$
f(t)=\sum_{m=-\infty}^{\infty} \sum_{n=-\infty}^{\infty} \Psi_{f}^{w}(m, n) \cdot \psi_{m n}^{*}(t)=\sum_{m=-\infty}^{\infty} \sum_{n=-\infty}^{\infty}\left\langle f, \psi_{m n}\right\rangle \cdot \psi_{m n}^{*}(t) .
$$

The CWT due to the above-mentioned discretized manner, however, is considered as wavelet frame transform (WFT) or wavelet series. The discrete wavelet transform (DWT) carries out so-called multi-resolution analysis for both decomposition (analysis) and reconstruction (synthesis) of the original time series. It is thought of the WFT coefficients $\Psi_{f}^{w}(m, n)$ as digital filters as which the original time series is passed through low-pass filters to decompose into low frequency components and passed through high-pass filters to analyze into high frequency components. Thus, the DWT uses two functions: basic wavelet function $\psi_{m n}(t)$ (mother wavelet) and associated scaling function $\phi_{m n}(t)$ (father wavelet) in which the scaling function is used for low-pass filtering, the wavelet function for high-pass one. It is also required that such scaling functions $\phi_{m n}(t)$ are orthogonal themselves. The scaling functions can be also expressed as the same manner as the wavelet ones (2.4).

The scaling and wavelet functions at lower resolution $\phi_{m}(t), \psi_{m}(t)$ can be expressed by a weighted sum of shifted version of corresponding functions at higher resolution $\phi_{m}(2 t), \psi_{m}(2 t)$ as follows:

$$
\phi_{m}(t)=\sum_{n=-\infty}^{\infty} g[n] \cdot \phi_{m}(2 t-n) ; \quad \psi_{m}(t)=\sum_{n=-\infty}^{\infty} h[n] . \psi_{m}(2 t-n),
$$

where $g[n], h[n]$ : scaling wavelet coefficients and wavelet function ones, respectively. Accordingly, the relation between $\mathrm{g}[\mathrm{n}]$ and $\mathrm{h}[\mathrm{n}]$ can be obtained $h[n]=(-1)^{n} g[1-n]$.

Using the wavelet and scaling functions, the DWT's wavelet decompositions of $f(t)$ in (2.5) can be represented at certain level $m_{0}$ by two summations as follows:

$$
\begin{gathered}
f(t)=\sum_{n=-\infty}^{\infty}\left\langle f, \phi_{m_{0} n}\right\rangle \phi_{m_{0} n}(t)+\sum_{m=m_{0}}^{\infty} \sum_{n=-\infty}^{\infty}\left\langle f, \psi_{m n}\right\rangle \psi_{m n}(t), \\
f(t)=\sum_{n=-\infty}^{\infty} a_{m_{0}}[n] \phi_{m_{0} n}(t)+\sum_{m=m_{0}}^{\infty} \sum_{n=-\infty}^{\infty} d_{m}[n] \psi_{m n}(t)
\end{gathered}
$$

The first summation refers to the low resolution or coarse approximation of $f(t)$ at the level $m_{0}$ that corresponds to the low-frequency band components, whereas the second one is sum of high-resolution details of $f(t)$, corresponds to the high-frequency band ones. The DWT's decompositions at level ' $M$ can be expressed by the summation of approximation coefficient at final level $M\left(\mathrm{~A}_{M}\right)$ and sum of detail coefficients at lower level $m \leq M\left(D_{m}\right)$ :

$$
f(t)=A_{M}+\sum_{m=1}^{M} D_{m}
$$

Figure 1 shows DWT's three-level wavelet decompositions, also called as a filter-bank tree (here $M=3$ ). Haar's scaling and wavelet functions (known as Daubechies family's 
DB1 wavelet) have been used in this study due to its compact support and localization (see Fig. 2).

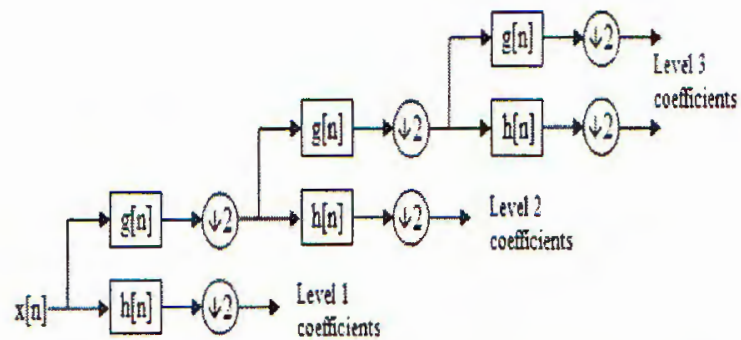

Fig 1. Scheme of three-level decompositions
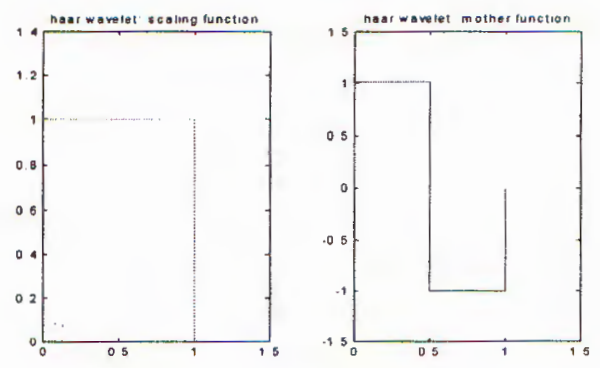

Fig. 2. Haar scaling and wavelet functions

\section{ENERGY OF DECOMPOSITION, INTERMITTENCY FACTOR AND INTERMITTENT ENERGY, ENERGY OF CROSS CORRELATION}

The DWT's coefficients represent amplitude of wavelet decompositions associated with the time-frequency information at certain spectral bands. Energy of wavelet decompositions, however, plays more significant role than the amplitude themselves, because the energy of wavelet decompositions relates to the energy contribution of coefficients on total energy of original time series. Energy of wavelet decompositions is defined as the same way as that of discrete time series as the square of amplitude of wavelet decompositions.

Intermittency factor of wavelet decompositions, described by the means of time factor or percentage is measured as a ratio between total time fraction of higher energy state over energy threshold and entire time interval of wavelet decompositions. The energy threshold has been defined as twice the average energy of wavelet decompositions $[6,7]$. Intermittent energy, moreover, is defined as percentage of energy contribution of higher energy state in wavelet decompositions over their total energy.

Cross correlation between turbulent components and turbulent-induced forces has been detected in the temporal-spectral structure using proposed term of cross energy. Cross energy is defined as a product operator between energy of wavelet decompositions of turbulence and corresponding energy of wavelet decompositions of their induced forces at the same decomposition level.

\section{EXPERIMENTAL PROCEDURE}

Turbulence and turbulent-induced forces have been determined simultaneously in the open-circuit wind tunnel of the Bridge and Wind Engineering Laboratory, Kyoto University using rectangular section model with slender ratio $B / D=5$ (see Fig. 3). Two turbulent components (longitudinal $u(t)$ and vertical $w(t)$ ) have been measured thanks to $X$-type hot-wire anemometer (Model 0252, Kanomax Co., Ltd,, Japan). Two induced forces (lift $L(t)$ and moment $M(t)$ ) have been also obtained using dynamic multicomponent load-cells (Model LMC-3501-30N, Nissho Electric Works Co., Ltd.; Japan). Three turbulent flow conditions have been generated by grid device at intensities of turbulence: $I_{u}=11.46 \%, I_{w}=11.23 \%$ (case 1), $I_{u}=10.54 \%, I_{w}=9.78 \%$ (case 2) and $I_{u}=9.52 \%, I_{w}=6.65 \%$ (case 3 ) corresponding to mean wind velocities $U=3.6$ and 9 
$\mathrm{m} / \mathrm{s}$, respectively. All electric signals of turbulences and turbulent-induced forces were filtered by $100 \mathrm{~Hz}$ low-pass filters (E3201, NF Design Block Co., Ltd., Japan) before passed through A/D converter (Thinknet DF3422, Pavec Co., Ltd., USA) with sampling rate at $1000 \mathrm{~Hz}$ over $10 \mathrm{~s}$ time interval.
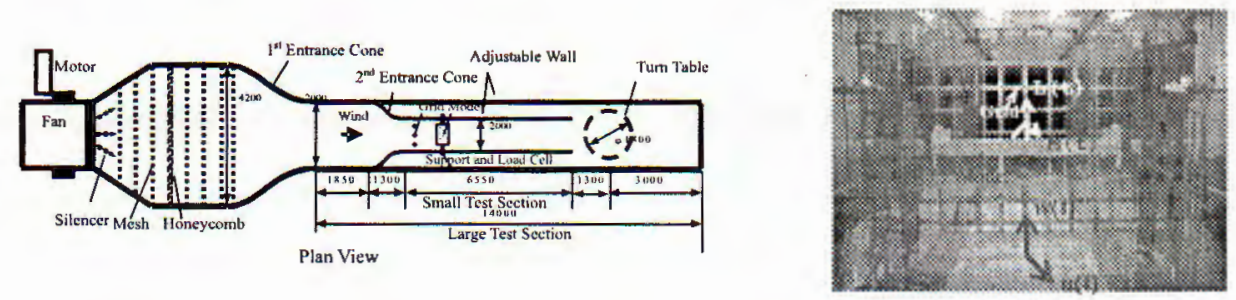

Fig. 3. Configuration of open-circuit wind tunnel and experimental set-ups
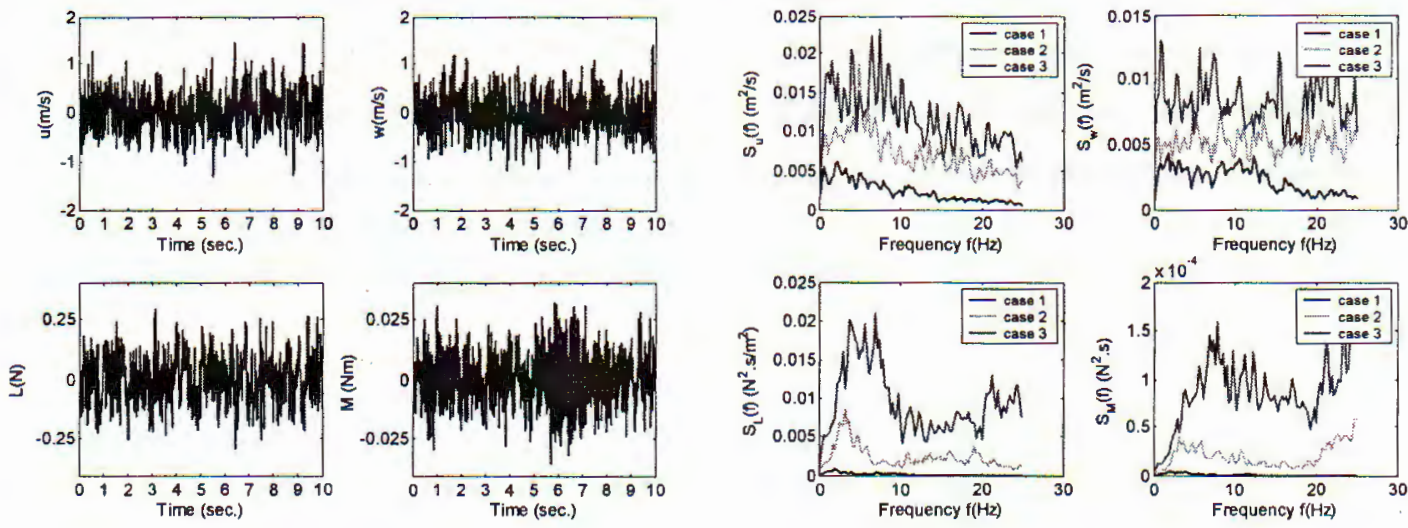

Fig. 4. Time series of turbulence and forces (case 1) and their power spectral densities

Fig. 4 shows time series of $u, w$-turbulent components and turbulent-induced forces at the certain turbulent flow (case 1) and power spectral densities (PSD) of turbulence and induced forces at all three turbulent flows.

\section{RESULTS AND DISCUSSIONS}

The DWT of seven-level wavelet decompositions (consisting of eight coefficients $D_{1}$, $\left.D_{2}, D_{3}, D_{4}, D_{5}, D_{6}, D_{7}, A_{7}\right)$ has been used with measured turbulences and cross correlation between turbulence and induced forces. Figure 5 shows the energy of wavelet decompositions of $u$ and $w$ - components in the turbulent case 1 represented both in time domain $(0 \div 10 \mathrm{~s})$ and frequency band $(0 \div 500 \mathrm{~Hz})$. It notes that cut-off frequency here is $500 \mathrm{~Hz}$ as half of the sampling rate. Figure 6 indicates Fourier-based power spectral densities (PSD) and associated frequency bands corresponding to wavelet decompositions. As can be seen that wavelet decompositions concentrate on certain frequency bands and spectral resolution increases twice with an increase of decomposition levels (at high scale). For example, coefficient $D_{1}$ contains the long and high frequency band of $250 \div 500 \mathrm{~Hz}$ (low resolution), while $A_{7}$ focuses on short and low band of $0 \div 3.91 \mathrm{~Hz}$ (high resolution). As a result, the temporal-spectral information of wavelet decompositions is completely 
known from this multi-resolution analysis. Low-level wavelet decompositions such as $D_{1}$, $D_{2}$ associated with high frequency bands (eontaining $125 \div 500 \mathrm{~Hz}$ spectral components) do not contribute much on total energy of turbulence, thus they can be considered as system noise. As eliminating low-level decompositions or high-level ones from signals, it is as a principle of the DWT-based low-band or high-band digital filters of turbulence.
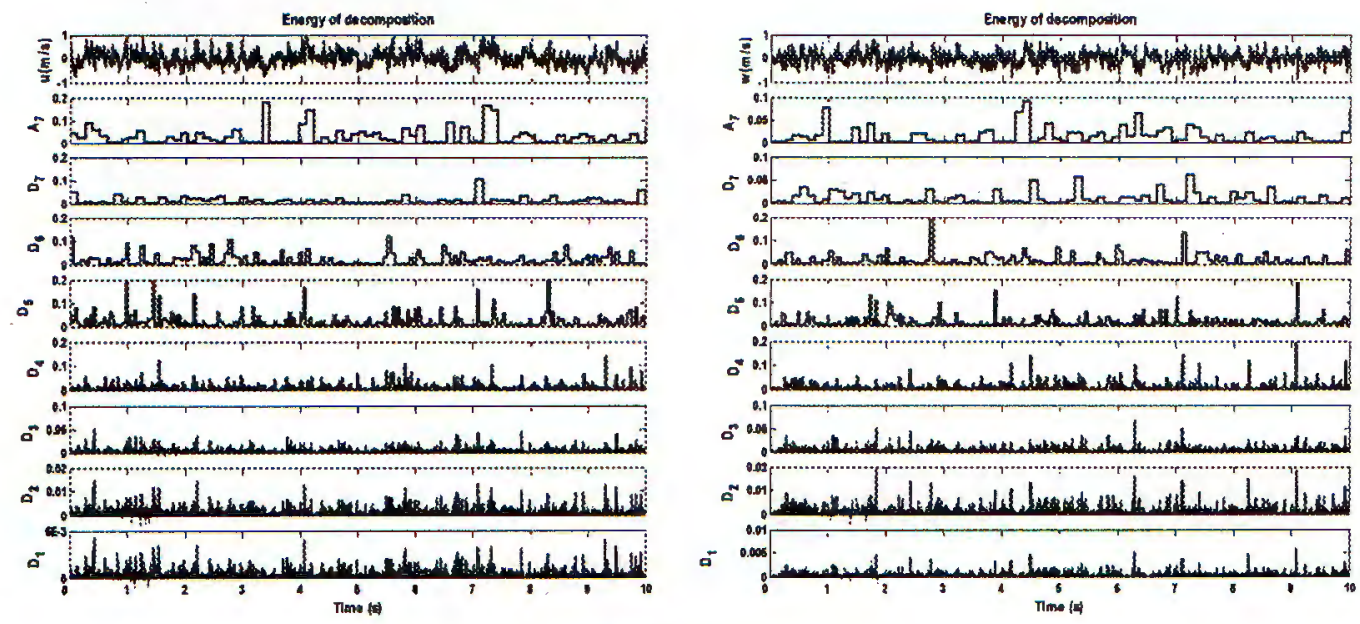

Fig. 5. Energy of seven-level wavelet decompositions of $u, w$-turbulences (case 1)
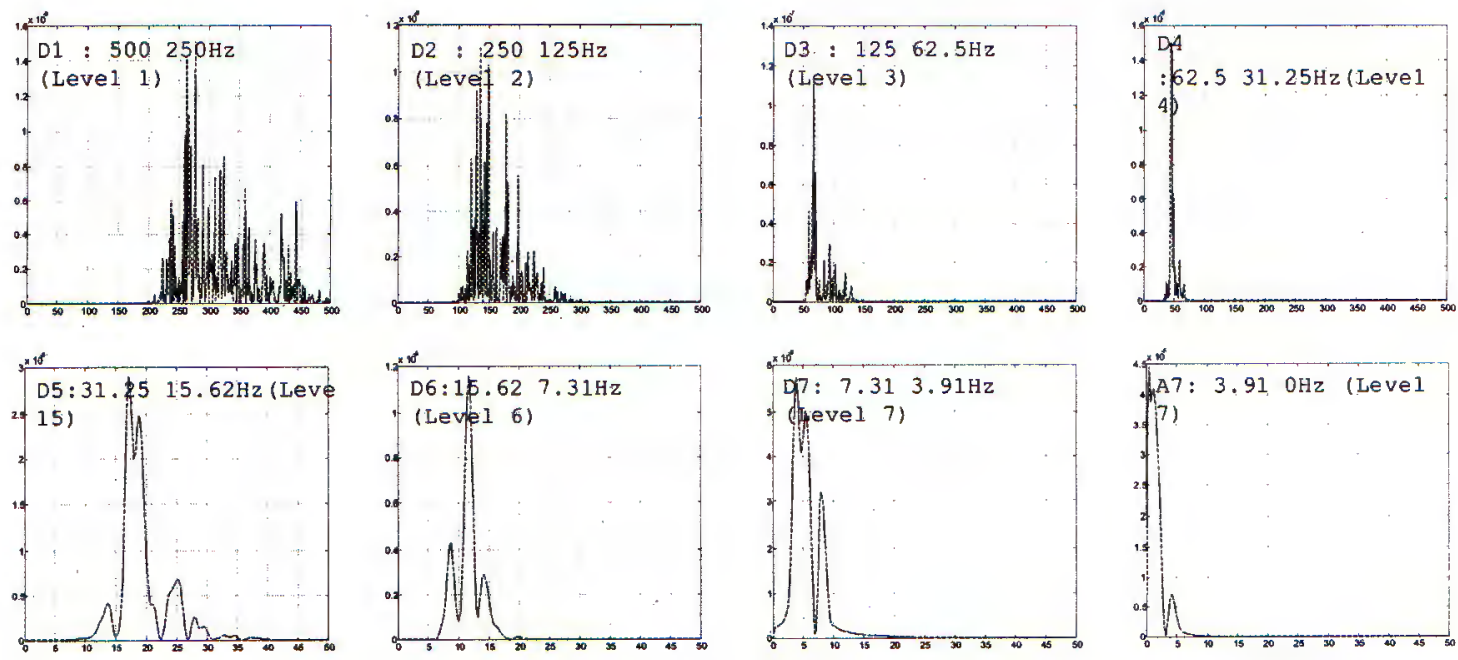

Fig. 6. Power spectral densities of seven-level wavelet decompositions $\left(D_{3} \div \mathrm{D}_{7}, A_{7}\right)$

Fig. 7 expresses energy contribution, intermittency factor and intermittent energy of wavelet decompositions of $u, w$ components in the three cases of turbulent conditions, quantified in percentage. First at all, results of the case 1 from Fig. 7 are quoted for consideration with the energy of decompositions presented in Fig. 5. As can be seen from Fig. 7, low frequency coefficients contribute dominantly on total energy of turbulence. Concretely, $A_{7}(0 \div 3.91 \mathrm{~Hz}$ spectrum $), D_{6}(7.81 \div 15.62 \mathrm{~Hz})$ and $D_{5}(15.62 \div 31.25 \mathrm{~Hz})$ 
contribute $30.24 \%, 20.29 \%, 20.61 \%$ (summed as $71.14 \%$ ) on total energy of u-component, and $18.90 \%, 22.56 \%, 20.77 \%$ (summed as $62.23 \%$ ) of w-component, respectively. These findings correspond to the energy amplitude of such coefficients $D_{5}, D_{6}, A_{7}$ shown in Fig. 5. Summed energy of high frequency coefficients $D_{1}, D_{2}, D_{3}$ of $62.5 \div 500 \mathrm{~Hz}$ spectrum, furthermore, holds only $5.39 \%$ of total energy of $u$-component and $7.31 \%$ of that of $w$ component. Thus, such coefficients $D_{1}, D_{2}, D_{3}$ can be considered as high frequency system noise, and eliminated without a loss of accuracy from reconstruction of original time series. Next, the intermittency can be revealed from Fig. 7 that the intermittency factor gets small, whereas the intermittent energy has large. This explains that high energy events hold very short time, but they contribute almost energy. For example, in the coefficients of $u$-component in the case 1 , the high energy events in $A_{7}$ only take $14.24 \%$ in total time but hold $50.78 \%$ in total energy (For short, it is written $12.24 \%(50.78 \%$ ) in $\left.A_{7}\right), 15.36 \%(56.85 \%)$ in $D_{6}, 14.44 \%(59.33 \%)$ in $D_{5}$. Finally, in all cases of turbulence, the high energy events of $u$-component take between $12 \% \div 18 \%$ in time but hold $50 \% \div 65 \%$ in energy, and those of $w$-component take $14 \% \div 18 \%$ in time, hold $45 \% \div 65 \%$ in energy.
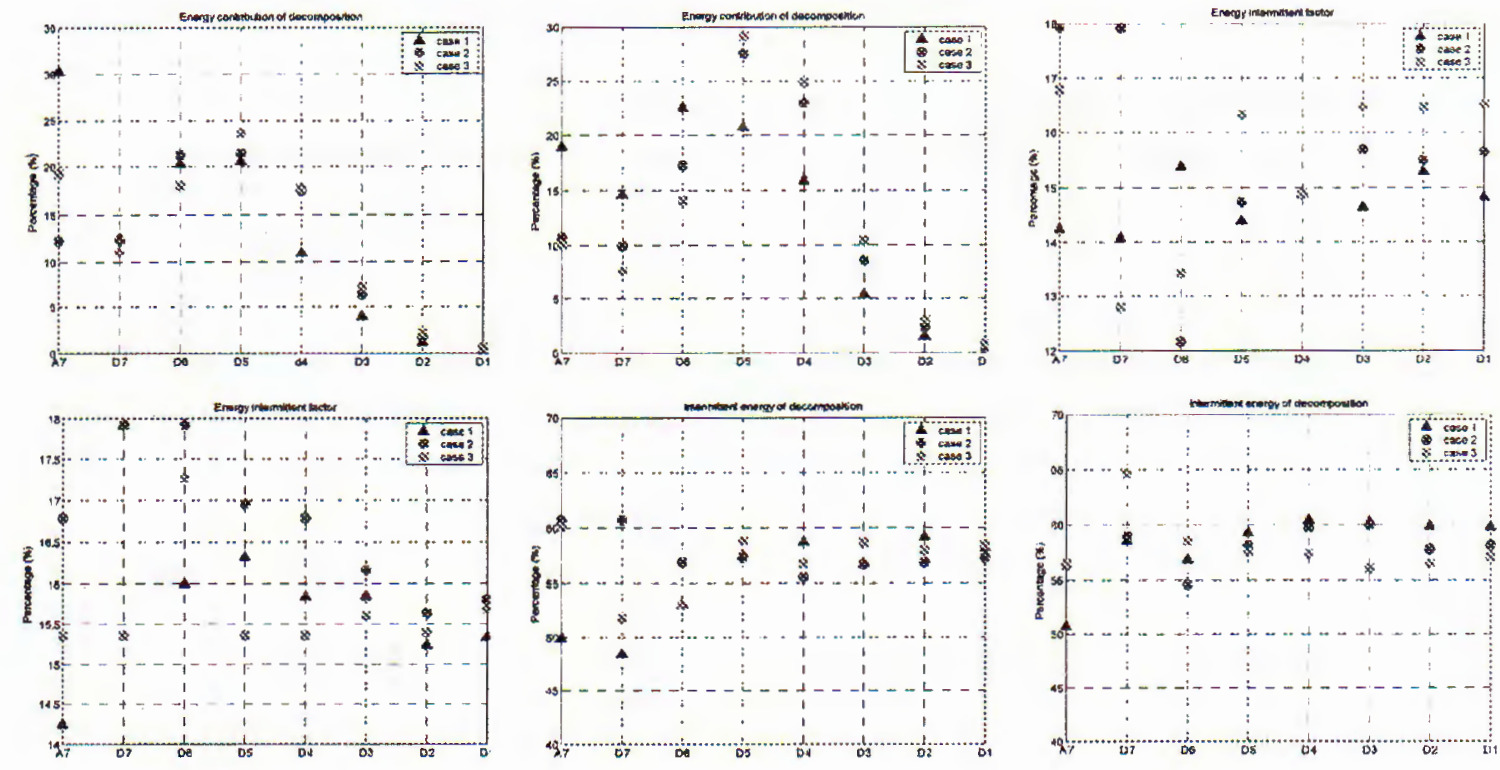

Fig. 7. Energy contribution of decompositions (upper), intermittent factor (middle) and intermittent energy (lower) of $u$-component (left side) and $w$-component (right side)

Cross energies of wavelet decompositions at all corresponding levels between $w$-turbulence and induced lift, moment (upper row) and between $u$-turbulence and lift, moment (lower row) in turbulent case 1 are expressed in Fig. 8. High cross correlation between turbulence and induced forces can be detected in both the frequency band and time domain. As can be seen from Fig. 5 and Fig. 8, it seems high energy events of turbulence-force correlation do not occur simultaneously with those of turbulence at the same frequency bands, thus it implies that no consistent relation between turbulence and induced forces in the time-frequency domains. For example, in the high-level wavelet decomposition A7 $(0 \div 3.91 \mathrm{~Hz})$ high energy events in $w$-turbulence occur at roughly $1 \mathrm{~s}, 4.3$ 
cross energy between $w$-turbulence and lift are obtaining at about $2 \mathrm{~s}, 4.3 \mathrm{~s}, 4.8 \mathrm{~s}, 5.3 \mathrm{~s}$, $6.8 \mathrm{~s}, 7.3 \mathrm{~s}, 8.8 \mathrm{~s}$; between $w$-turbulence and moment at $2 \mathrm{~s}, 3.2 \mathrm{~s}, 4.3 \mathrm{~s}, 4.7 \mathrm{~s}, 5.2 \mathrm{~s}, 7 \mathrm{~s}$, $7.3 \mathrm{~s}, 9.5 \mathrm{~s}$. The same comments can be revealed from other wavelet decompositions as well as $u$-turbulence and correlation between $u$-turbulence and induced lift, moment.

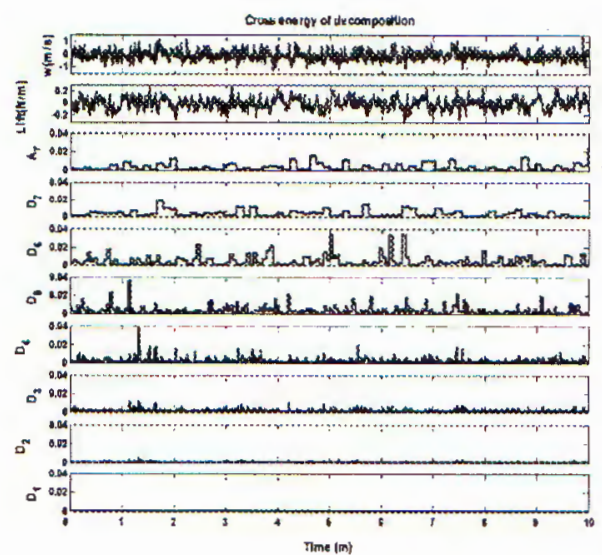

crose enengy of desomposition

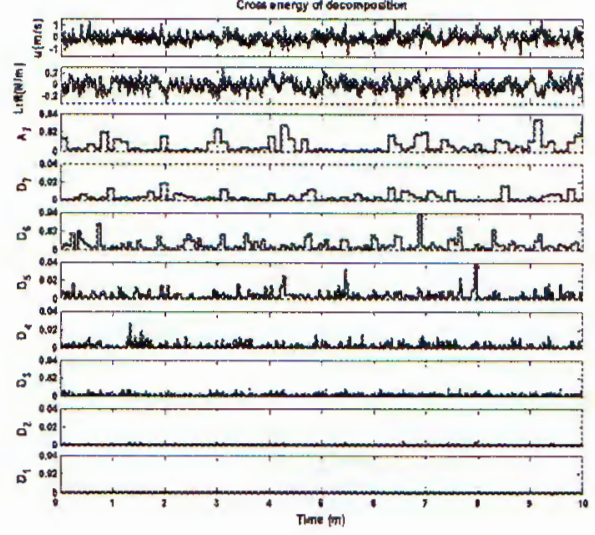

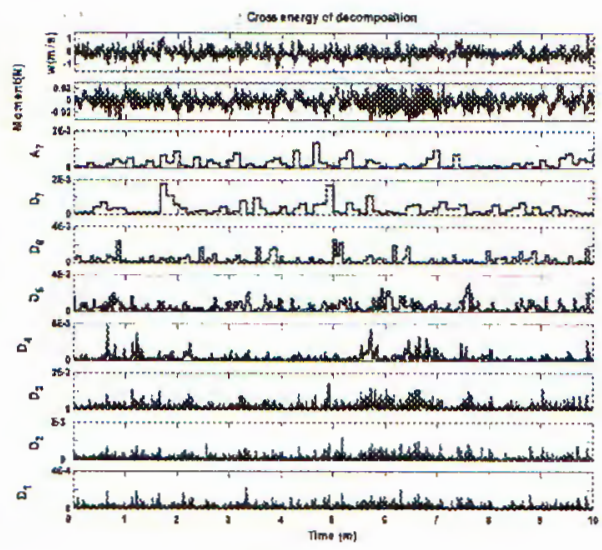

Eroses whergy of decombosition

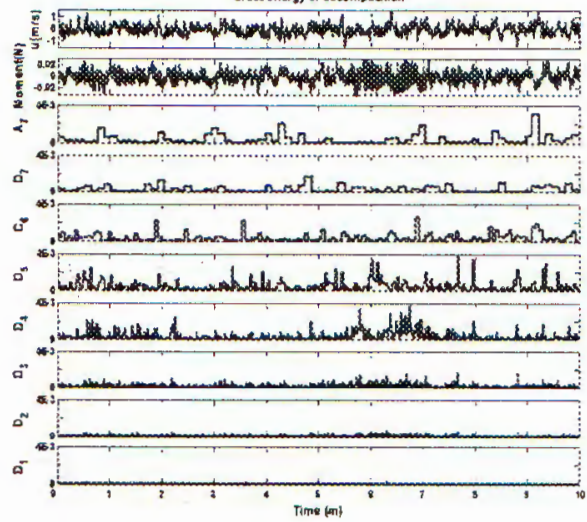

Fig. 8. Cross energy of seven-level decompositions between $u, w$-turbulent components and induced lift, moment

\section{CONCLUSION}

Artificial turbulence and correlation between turbulence and induced acrodynamic forces have been discussed here thanks to orthogonal-based wavelet decomposition using experimental data from the wind tunnel test. Some concepts such as intermittency factor and intermittent energy, cross energy of multi-level wavelet decompositions have been used for studying turbulence and turbulence-force correlation. It can be concluded with some followings:

Low-band spectral components contribute dominantly on total energy of turbulence. Especially, high energy events relating to instantaneous peaks of the turbulence exist shortly and discretely but contain almost the energy, it implies the intermittency as nature of wind turbulence. Spectral components of turbulence and induced forces vary with both 
the time and the frequency, it means that turbulence and induced forces as well exhibit as non-stationary characteristics.

High energy events of turbulence and induced forces do not simultaneously occur on the time domain at the same frequency bands. Thus, no reliable linkage can be observed in the turbulence-force high correlation corresponding to the high energy events occurring in turbulence.

Since turbulence and induced forces exhibit as non-stationary nature, and relation between turbulence and forces is still not consistent, thus conventionally analytical tools based on Fourier spectral transformation can produce unpredictable risks for aerodynamic response evaluation in aspects of experiment, computation and simulation.

Acknowledgements. First author would acknowledge to the Prof. M. Matsumoto, Prof. H. Shirato and Dr. T. Yagi of the Bridge and Wind Engineering Laboratory, Department of Civil and Earth Resources Engineering, Kyoto University, Japan for their supports during this work. The thanks would express to Messrs K. Yamane, T. Furukawa and Y. Sumikura for their collaboration in the wind tunnel experiments. The paper is partly supported by the Program of research in natural science.

\section{REFERENCES}

1. A. Boggess, F. J. Narcowich, A First Course in Wavelets with Fourier Analysis, Prentice-Hall 2002.

2. A. Bruns, Fourier-, Hilbert- and wavelet-based signal analysis: are they really different approarches, Journal of Neuroscience Methods 137 (2004) 321-332.

3. R. Camussi and G. Guj, Orthonormal wavelet decomposition of turbulence flows: intermittency and coherent structures, Journal of Fluid Mechanics 346 (1997) 177-199.

4. I. Daubechies, Ten lectures on wavelets, Society for Industrial and Applied Mathematics (SIAM) 1992.

5. P. D. Nguyen, Damping identification in multi-degree-of-freedom systems using continuous wavelet transform, Vietnam Journal of Mechanics 27 (1) (2005) 41-50.

6. M. Farge, Wavelet transforms and their applications to turbulence, Annual Review on Fluid Mechanics 24 (1992) 395-457.

7. M. R. Hajj, Intermittency of energy-containing scales in atmospheric surface layer, Journal of Engineering Mechanics 125 (7) (1999) 797-803.

8. A. Kareem, T. Kijewski, Time-frequency analysis of wind effects on structures, Journal of Wind Engineering and Industrial Aerodynamics 90 (2002) 1435-1452 .

9. T. Kitagawa, T. Nomura, A wavelet-based method to generate artificial wind fluctuation data, Journal of Wind Engineering and Industrial Aerodynamics 91 (2003) 943-964.

10. T. H. Le, Correlation detection of turbulence and turbulent-induced forces using continuous and discrete wavelet transforms, Proceedings of $3^{\text {rd }}$ Vietnam Conference on Mechatronics (2006), Hanoi, Vietnam.

11. H. W. Tieleman, M. R. Hajj, I. M. Janajreh, T. A. Reyhold, C. P. W. Geurts, Velocitypressure correlation in stagnation and separation regions on surface-mounted prisms, Journal of Wind Engineering and Industrial Aerodynamics 77-78 (1998) 567-578.

12. B.A. Zeldin, P.D. Spanos, Random field representation and synthesis using wavelet bases, Journal of Applied Mechanics 63 (4) (1996) 946-952. 


\section{PHÂN TÍCH WAVELET TRỰC GIAO CƯA VẬN TỐC GIÓ BIẾN THIÊN, MỐI TƯƠNG QUAN GIŨ̃A VẬN TỐC VÀ LỰC PHÁT SINH}

Mô hình hiện nay về mối liên hệ giữa các thành phần vận tốc gió biến thiên và lực khí động phát sinh chứa đựng rủi ro trong đánh giá đáp ứng khí động lực ngẫu nhiên của công trình. Các nghiên cứu tiếp tục về mối tương quan này nhằm mục đích nâng cao hiểu biết trong phương pháp phân tích đáp ứng khí động lực và các mô phỏng trong thí nghiệm hầm gió. Phép biến đổi wavelet liên tục và rời rạc hiện đang được áp dụng để trình bày và phân tích tín hiệu thời gian đồng thời trong miền thời gian và tần số, đồng thời tìm ra các đặc trưng ngắn hạn ân chứa trong tín hiệu thời gian. Báo cáo này sẽ trình bày việc áp dụng phân tích wavelet rời rạc sử dụng các hàm wavelet trực giao nhằm nghiên cứu sự gián đoạn thời gian của tín hiệu vận tốc gió biến thiên và dò tìm mối tương quan giữa vận tốc và lực phát sinh trong không gian thời gian và tần số, trên cơ sở đưa ra khái niệm năng lượng chéo giữa các hệ số tách wavelet. Các số liệu vận tốc gió biến thiên và lực khí động dùng trong nghiên cứu này được xác định từ đo đạc trực tiếp trên mô hình trong phòng thí nghiêm hầm gió. 